\title{
TEXT review
}

\section{Writing Trauma and Testimony: literary critique and manifesto}

\section{review by Bridget Haylock}

Gestures of Testimony: Torture, Trauma and Affect in Literature Michael Richardson Bloomsbury Academic London 2016

Michael Richardson's Gestures of Testimony: Torture, Trauma and Affect in Literature (2016), is a work of considerable scholarship around the cultural and ethical representation of torture. This gesture is in itself towards that which he argues is unrepresentable, a position consistent with the problematic representation of trauma. Richardson contends that there is 'an urgent need for torture and the war on terror to enter more fully into literature' so that it be known more widely and fully as an event experienced 'with a terrible and traumatic aftermath' (8). In seeking how to write torture, Richardson mobilises readings of tortured-prisoner poetry, memoir, legal memoranda, film, photography and fiction; he draws on theories of power, affect, trauma, and testimony to develop in Gestures of Testimony, a critique, and as he suggests, a manifesto of how fiction might be brought into service to achieve justice driven by the 'charge of radical empiricist philosophers to create the new' (10).

Richardson meticulously develops his argument through chapters such as 'Tortured Bodies', 'Reading Torture' and 'Seeing Torture'. However for this Special Issue, the chapters 'Writing Trauma' and 'Witnessing and the Poetics of Trauma' are of most interest. Richardson tasks the book with addressing the question of 'how literature might bear witness to torture', which must somehow incorporate the traumatic affect generated by the act (79). In seeking how to address his own writing practice, to write torture and, by extension, trauma, into fiction, Richardson, discovers structure in the film Incendies for example, that offers a 'fictive aesthetic and narrative for the expression of violence, torture and trauma' (90). A traumatic event is performed invisibly, 'splintered from experiential time'; the traumatic rupture occurs as a cut 'between the shots' (94). Richardson argues that this excision of the explicit event allows space for the traumatic affective aftermath, and the resistance to language of trauma is highlighted by temporal disjuncture.

As he explores the relation of writing to trauma, Richardson introduces reflective writing into his discourse. This serves an ironic purpose, it personalises his discussion about torture and performs the affectivity of the trauma he feels as a reader and writer of torture, 'affected in the act' as he says (99). Richardson's aim in his creative writing practice is to discover how to illuminate human rights abuses, not elsewhere documented. He argues that writing shares a particular affinity with trauma, in the temporal relationship of a continuous ever-present past influencing the future. He sees that it is in literature, writing, that the narration of the known and unknown can occur and also 'express the shifting, uncertain, and non-narrative relations between the two' (104). In his own writing practice as he writes of torture, bodily encounter, Richardson discovers a fear of 'some awful descent into the writing self', and to which he is reluctant to admit to those around him (111). 
He acknowledges the work of deconstructivists such as Paul de Man, who he writes saw 'no meaningful relation between the inside and outside of a text' (123), as well as the contribution of J. Hillis Miller, to whom the ethics of reading text is important to Richardson's concern to testimony. While he praises those post-structural strategies of literary trauma theories that trace trauma's slippage through texts, he asks what the gaps, silences, and absences actually do to the reader affectively. In an analysis of Anne Michael's Fugitive Pieces (1996), Richardson arrives at a point where he contends that 'to be affected in the act of reading is to encounter the gestural capacity of literature, an intensity that escapes the page to change the state of the reading body' (127). He argues that Michael's work uses a tension between lyric language and traumatic event that generates affective intensity in the reader. Richardson discusses how the use of fragmentation, and continual gesturing beyond language reveals 'impossible depths beneath traumatic surfaces' where he sees in the temporal and spatial layering an enfolding 'to gesture at that which can never be represented' (135). It is to Michael's poetics of witnessing that Richardson gestures when seeking to write trauma.

Richardson writes that it is openness to traumatic affect that can impel writing about trauma; 'gestures of testimony might enable literature to refuse the claims of unrepresentability and bring into writing what once seemed to deny language the very capacity to exist' (165). It is linguistic gestures from those courageous enough to bear witness, and embrace their writing selves whose testimony sheds light where otherwise dark. 